\title{
Defensive mechanisms and personality structure in an early adolescent boy: Process and outcome issues in a non-intensive psychoanalytically oriented psychotherapy
}

\author{
Daniela Di Riso $^{1 \bowtie}$, Alessandro Gennaro ${ }^{2}$, \& Silvia Salcuni ${ }^{1}$
}

\begin{abstract}
The main aim of this paper is to empirically assess defense mechanisms trends and personality structure in a once a week psychoanalytically oriented psychotherapy with an early adolescent, affected by a General Anxiety Disorder (GAD). Assessment and outcome measure included the Shedler-Westen Assessment Procedure for Adolescents (SWAP-200-A); process was evaluated through defensive mechanisms analysis, using Defense Mechanisms Rating Scale (DMRS). The paper focused on 12 sessions divided into three periods, along 2 years of treatment. Quantitative and narrative profiles of SWAP-200-A and DMRS were integrated; a log linear procedure was chosen to assess defensive mechanisms trends longitudinally during the treatment. Moreover a Multiple Correspondence Analysis (MCA) was applied to DMRS to provide a map of the evolution of the patterns of defense mechanisms throughout the course of treatment. Personality assessment and defensive mechanisms showed an inhibited self-critical image with obsessive, narcissistic and disavowal patterns. According to trends during treatment phases, MCA analysis identified decreasing in defensive patterns, while mature defenses increased significantly. The study highlighted how non-intensive psychoanalytic psychotherapy can help early adolescents with clinical problems to improve their overall mental functioning. Outcome in terms of personality structural changes and process according to defense mechanisms were discussed to highlight improvement not just in symptomatology, but also in personality structure and functioning.
\end{abstract}

Keywords: process, outcome, personality, defenses mechanism

"Psychodynamic or psychoanalytic psychotherapy refers to a range of treatments based on psychoanalytic concepts and methods that involve less frequent meetings and may be considerably briefer than psychoanalysis proper. Session frequency is typically once or twice per week, and the treatment may be either time limited or open ended. The essence of psychodynamic therapy is exploring those

\footnotetext{
${ }^{1}$ Department of Developmental and Socialization Psychology (DPSS), Università degli Studi di Padova, Italy.

${ }^{2}$ Department of Pedagogical, Psychological and Didactical Sciences, Università del Salento, Italy.

$凶$ Corresponding author: Daniela Di Riso, PhD, DPSS, Via Venezia 8, 35140 Padova; email to: daniela.diriso@unipd.it
}

aspects of self that are not fully known, especially as they are manifested and potentially influenced in the therapy relationship" (Shedler, 2010, p.98)

The empirical evaluation of outcome and process in psychodynamic treatments with adults has developed rapidly over the last years (Gerber et al., 2011; Shelder, 2010). Progress in empirical studies on psychotherapy outcome and processes with children and adolescents has lagged behind compared with adult literature, especially in the psychodynamic-psychoanalytical field (Kazdin \& Weisz, 1998; Shirk \& Russell, 1996). Recent papers have pointed out that psychodynamic treatment of children and adolescents presents not always consistent results (e.g. Gilboa- 
Schechtman et al., 2010). Midgley and Kennedy (2011) concluded that psychodynamic treatments might result effective for a wide range of childhood disorders, when outcome is measured with standardized research tools. Although systematic reviews of empirical literature about the treatment of children and adolescents have been produced in terms of outcome, efficacy and effectiveness, they have scarcely focused on psychodynamic psychotherapies process (Kennedy, 2004; Kennedy \& Midgley, 2007; Shirk \& Russell, 1996; Weisz \& Hawley, 2002).

Concerning clinical process, few empirical studies addressed the mechanisms of the therapeutic action in youth in psychodynamic-psychoanalytic treatments (Kazdin, 2009; Llewellyn \& Hardy, 2001). As above mentioned, recent literature has shown that intensive psychodynamic interventions seem to be effective with younger children (Deakin \& Nunes, 2009) and adolescents (Lock, La Grange, Agras, Moyes, Bryson, \& Jo, 2010). Some authors have tried to identify the 'active ingredients' that explain the process of a successful psychodynamic clinical intervention in youth (Fonagy, Target, Cottrell, Phillips, \& Kurtz, 2005), such as the natural inner conflict between childish-dependency versus youthautonomy with parents, the importance of have or gain a secure and comfort base which can permit the high activation of explorative and affiliative system. Recently, there is now a renewed interest in studies that empirically assess the nature of child and adolescent psychodynamic psychotherapy, capturing structural changes due to clinical intervention and/or children in session-behavior (e.g. Karver, Handelsman, Fields, \& Bickman, 2005).

Few studies have introduced validated personality measures at the beginning and end of the treatment to empirically control changes in personality structure. One of the most assessed outcome tools, the adolescent adaptation of the Sheldon West Assessment Procedure (SWAP-200-A), was devised to assess personality structure within a psychodynamic approach (e.g. Westen, Gabbard, \& Blagov, 2006). Studies of construct and concurrent validity of SWAP-200-A have increased in these last years (Westen, Shedler, Durrett, Glass, \& Martens, 2003; Williams, Ferrara, Aloi, \& Gazzillo, 2009). Specific studies of single cases of adolescents have already been carried out using the SWAP-200-A to improve assessment procedures (Porcerelli, Cogan, \& Bambery, 2011). However, SWAP-200-A has never been used to connect personality change with process issues.

Children's defensive functioning was also assessed through numerous measures (e.g. Defense Mechanism Inventory - Children Version; Cramer, 1991; Comprehensive Assessment of Defense Style; Laor, Wolmer, \& Cicchetti, 2001). However, although reliability and validity were encouraging, these tools have been applied to projective measures administered to referred children and adolescents, or the measures have been developed as self-report questionnaires. They did not evaluate defensive mechanisms arising in vivo in the therapeutic setting, as with adult patients (e.g. Porcerelli, Dauphin, Ablon, Leitman, \& Bambery, 2007). All these tools can be defined as "in progress", because their reliability and validity have been scarcely supported until now. Although still quite controversial, the use of transcripts of audio- or video-taped psychotherapy sessions is developing in single-case study approaches, focusing on selected transcribed sessions, representative of the core therapeutic periods of the intervention (Chazan \& Wolf, 2002; Duncan, 2006). However, all of these papers involve child patients who underwent twice-weekly or more intensive psychoanalytically-oriented psychotherapies (Chazan \& Wolf, 2002; Duncan, 2006). Moreover, these studies have explored one, or a relatively small number of child psychotherapy cases, in order to investigate the process of psychotherapeutic change from multiple perspectives, and in great depth. A growing body of literature demonstrating changes in personality structure and or defense use over longterm psychodynamic therapy in adults, however no studies have empirically examined this topic in youth (Lingiardi, Shedler, \& Gazzillo, 2006; Di Riso et al., 2011). Despite the long tradition addressing defense mechanisms as an active ingredient contributing to a good psychotherapy,to our knowledge no studies have empirically assessed the process change of defense mechanisms in child and adolescent patients involved in non-intensive psychoanalytic psychotherapy, considering possible changes in personality structure (Porcerelli et al., 2011; Di Riso et al., 2011; Kazdin, 2000a, 2000b).

\section{Aim and hypotheses}

By reexamining the therapy transcripts for defense use and personality structure, this paper provides a systematic case study of a non-intensive psychoanalytic psychotherapy in youth. As Gerber (2004) pointed out, in child and adolescent treatments, distinctions should be made between intensive psychoanalysis (up to 5 times weekly), and nonintensive psychoanalytic psychotherapy treatments (weekly) in terms of outcome and process.

The main aim of this paper is to empirically evaluate 12 session of a 2 years audio-recorded nonintensive psychoanalytically oriented psychotherapy with a 12 years old patient, Gabriele, in terms personality structure (outcome) and defensive mechanisms (process). According to the main aims, the following exploratory hypotheses have been made:

1) Outcome: A reduction in anxiety psychopathological symptoms (DSM-IV) and an improvement in personality functioning (SWAP-200-A) were expected, as assessed at the beginning and end of the therapy (Hypothesis 1). 


\section{2) Process:}

a) A significant decrease and a more flexible use of defensive mechanisms were expected. Specifically, a reduction in Gabriele's dysfunctional mechanisms (DMRS) and an increase in more mature ones were expected from this long-term treatment (Hypothesis 2).

b) The quantitative reduction in defense mechanisms (DMRS) is reflected in an improvement of the defense mechanism patterns over time, characterizing the patient sessions $(\mathrm{Hy}-$ pothesis 3).

\section{Method}

\section{Case study ${ }^{1}$}

Gabriele was a 12-year-old early adolescent Italian boy, when he was referred by his parents to a University Service that offered private practice in the community. He presented a very high level of anxiety and obsessive-compulsive symptoms. The DSM-IV diagnosis was General Anxiety Disorder (GAD). Some criteria for Obsessive Compulsive Disorder (OCD) were also met, such as the presence of compulsion to do repetitive behaviors (e.g., ordering, checking) driven to perform in response to an obsession and aimed at reducing anxiety and preventing some dreaded event or situation. He grew up in an intact family of a high socioeconomic level and had four younger siblings. The main core of Gabriele's symptomatology regarded pervasive acute anxieties about school achievement and ability to complete schools tasks (without any real basis), anxieties about his parents' physical and socioeconomic well-being. Also obsessive and compulsive behaviors were observed, including maintaining all his books and his wide collection of DVD movies in very precise order, the repeatedly checking that doors were closed. Gabriele is totally involved in school and study. He reported having few hobbies (reading and personal computer) and showed no form of pleasure when talking about them. Parents' attempts to cope with Gabriele's requests to be reassured seemed to be useless, and they were unable to contain and lower his anxiety. They showed feelings of impotence, helplessness, and guilt.

\section{Therapist}

The therapist was a certified clinical psychologist with 3 years' experience with children and adolescents. She was in clinical training to become a psychotherapist, and attended a psychoanalytically oriented training program, and was constantly supervised throughout Gabriele's treatment.

\section{Treatment}

Gabriele underwent three assessment sessions and one feedback session. In the feedback session, a once-a-week psychoanalytic oriented psychotherapy, previously proposed and accepted by his parents, was proposed and accepted by Gabriele. Treatment goals focused on reduction of anticipatory anxiety and obsessive behavior; shifting his high cognitive capacity and resources toward more pleasant and adaptive activities, such as friends, play, sports, to make his daily life more various and enjoyable. From a functioning perspective, an important therapeutic goal was to help Gabriele to be in contact with what he felt, to acknowledge his painful emotions, to limit his depressive-like mood, to indirectly overcome his difficulties in social adjustment; these goals were strictly connected with the possibility to attain a more realistic idea of the self, building a strong and consistent identity. The supportive therapy lasted 24 months and included approximately audio-recorded 50 sessions. During treatment period, parents underwent every two months with the therapist, just to be helped to understand and scaffold Gabriele's changes. In the first period the clinician mainly used empathic statements ("It seems to me it was so hard for you"). Then, interventions devoted to gradually name Gabriele's emotions ("What did you feel in this situation?" or "It seems to me you were angry"). This approach was chosen to help him first to feel that the clinical could empathize with his uncomfortable emotions and that those ones are not so scaring because they can be shared. Moreover, he was helped to differentiate between his own affective states and to disclose them more freely. This approach helped to build a positive therapeutic alliance, since from the earliest phases of the treatment, because Gabriele could experience a climate of acceptance of his fears, unacceptable for himself in the very first sessions. Then, by the last period of the treatment, the clinician used also interpretation, starting from the contents coming from the readings they shared during the sessions ("It seems to me you are sad as this soldier, so far from his family, and as him you expressed this emotions fighting with your mom"). Parents, therapist and Gabriele agreed with the end of the treatment before the beginning of the high school, in line with the patient general functioning improvement and following his desire to "try to do by myself". The end of therapy was very exciting for Gabriele, but he was able to feel also some fear of loneliness and to recognize the therapeutic support.

\section{Measures}

Defense Mechanisms Rating Scale (DMRS). The DMRS (Perry, 1990; Perry, 2001), in its latest version, allows the identification of 30 defensive mechanisms (Drapeau, De Roten, Perry, \& Despland, 2003) in video- or audio-taped sessions or transcripts of adult patients. Defensive mechanisms are arranged hierarchically on a seven level 
scale (1. Action, 2. Major-Image-distorting or Borderline, 3. Disavowal, 4. Minor Image-distorting or Narcissistic, 5. Other Neurotic, 6. Obsessional, 7. High Adaptive Level or Mature). The total percentage of defenses at each level forms the basis of a "defense profile" (see Figure 1 for the defensive profile in Gabriele's case), which represents the nature of the patient's functioning. Furthermore, as each level of defensive functioning is weighted according to its level of maturity, an overall defensive functioning score (ODF; a higher ODF means a better functioning) can be computed (Perry et al., 1998). In clinical samples based on whole interviews, scores usually range between 2.5 and 6.5. Two postdoctoral psychologists with at least three years of experience in coding DMRS (fully trained raters by a reliable judge originally trained by Dr. Perry) coded all the transcripts. Consensus ratings and reliability assessment were completed in all the sessions by the two coders. The two judges were blind and independent in each other scoring. Intra-class correlation coefficient was calculated. For this study, Intra Class Correlation (ICC) means for DMRS between the two raters was .69 (with SpearmanBrown Correction) indicating a moderate agreement, considered acceptable in literature. Wirtz and Caspar (2002) considered results to be satisfactory in terms of intra-class correlation coefficients consensus when varying between 0.64 and 0.95 . Reliability of the 7 defensive levels was considered to be good with an average intra-class coefficient of 0.79 .

The 200-item Shedler-Westen Assessment Procedure for Adolescents (SWAP-200-A). The 200-item Shedler-Westen Assessment Procedure for Adolescents (SWAP-200-A; Nakash-Eisikovits, Dutra, \& Westen, 2003, Westen, Dutra, \& Shedler, 2005; Westen \& Muderrisoglu, 2006), adapted from the SWAP-200, is a Q-sort instrument (Block, 1978) for assessing adolescent personality pathology. Each item describes thoughts, feelings, and behaviors associated with adolescent personality pathology and psychological health (Westen \& Shedler, 1999a, 2000; Westen, Shedler, \& Lingiardi, 2003). The items reflect constructs from Axis II and Axis I (DSM-III, DSM-IV, APA, 1980, 1994-2000) criteria functional diagnosis (Westen, 1998), and research on child and adolescent personality (Shedler \& Westen, 1998; Westen \& Shedler, 1999a). The raters organized the 200 statements into eight categories ranging from items that describe the patient very well to items that do not apply. In literature, Inter-rater reliability coefficients were good, and Cohen's $k$ ranged from .70 to .80 . Support for the validity of the SWAP-200-A is derived from its ability to predict relevant variables during assessment procedures (Di Lallo, Jones, \& Westen, 2009; Nakash-Eisikovits et al., 2003).

The SWAP-200-A could be interpreted at a nomo- thetic as well as idiographic level. Nomothetic interpretations were carried out following two profiles. The Personality Disorder (PD) profile concerned the results of ten dimensions (High Functioning, Paranoid, Schizoid, Schizotypic, Antisocial, Borderline, Hystrionic, Narcissistic, Avoidant, Dependant, Obsessive). The $\mathrm{Q}$-factor analysis ( $\mathrm{Q}$ profile) regarded 7 dimensions (Psychological Health, Antisocial, Emotional Dysregulation, Avoidant/Constricted, Narcissistic, and Histrionic, inhibited/self-critical) as well as a score on a healthy functioning index. Scores were transformed into T-score, where a score of 60 is the cutoff for a personality disorder, and T-scores between 55 and 59 constitute a personality disorder feature. The individual items that best describe the person can also be used to construct a narrative personality profile (e.g., Lingiardi et al., 2006). In respect with DMRS, other two trained, post-doc psychologist raters completed the SWAP-200-A blindly for the beginning and the end of treatment, reading fully transcribed clinical sessions. Then during a consensus meeting independent evaluations were compared. In this study, inter-rater agreement (Pearson r) for the intake and final sessions (i.e., of the average of both ratings), was $.67 / .80$ and $.60 / .75$, respectively. The mean ICC for the SWAP200-A was .72 (with Spearman-Brown Correction), indicating quite good agreement. Discussion of both nomothetic (PD profile) and ideographic (Q factor profile) levels at the beginning and the end of the treatment process can help clinicians conceptualize and document change, and predict outcome (Porcerelli et al., 2011).

\section{Procedure and analysis}

The present study is focused on 12 audiotaped and fully transcribed sessions (of a total of about 50), about $25 \%$ of the entire treatment. The selected sessions covered the whole treatment process (Chazan $\&$ Wolf, 2002). The 12 sessions were divided into three periods, each comprising a 4-session window. The first period ( $\mathrm{T} 1$, from the first to the fourth session) represented the first period after the intake. The second period ( $\mathrm{T} 2$, from the fifth to the eighth sessions) was defined as the central and core part of the treatment, about after a year of treatment. The third period ( $\mathrm{T} 3$, from the ninth to the last session) included the last sessions of the psychotherapy devoted to talking about the conclusion of the treatment. The choice of a four-session window was made to ensure that sessionto-session differences were leveled. SWAP-200-A was scored in T1 (assessment) and in T3 (outcome) and all 12 sessions were evaluated according to the DMRS. Clinical vignettes from the audio-taped sessions will be included to support data.

According to Hypothesis 1, Gabriele's case formulation -with quantitative and narrative profile of the SWAP-200-A- was reported at the beginning 
and the end of treatment.

According to Hypothesis 2, a two way log-linear model was chosen to assess trends of defensive mechanisms (DMRS levels) during the treatment (Periods). The log-linear model applied in this study made it possible to discuss data longitudinally (across Periods) according to the specific aims of the paper. In fact, when the goal is to assess process variables, longitudinal models can be helpful in identifying changes over time and determining whether the process is in line with expectations (Zeger, Irizarry, \& Peng, 2006). A log-linear model, fitted to cell frequencies derived from a $6 \times 3$ contingency table ${ }^{2}$, modeled relationships between these two variables. Both marginal and interaction effects were estimated. Row, column and interaction chi-square were reported. A saturated model was preferred, that fully explains all the relationships among the variables being analyzed, including all possible one-way effects. A saturated model imposes no constraints on the data and always reproduces the observed cell frequencies, with no degrees of freedom remaining (Knoke \& Burke, 1980). For all variables, tables that report the effect parameter estimates for the variables and their interactions (Knoke \& Burke, 1980) and the probability of the standardized parameters, were presented. The standardized form $(\mathrm{Z})$ can be used to assess which variables/interactions in the model were the most or least important for explaining the data. Significant effects ranging from $\mathrm{p}<.005$ to $\mathrm{p}<.05$ were be interpreted.

According to Hypothesis 3, a Multiple Correspondence Analysis (MCA; Benzecri, 1973a, 1973b) was applied to data obtained by DMRS. The MCA is a multidimensional procedure that describes how the modalities of a pool of qualitative variables tend to combine with each other. MCA performs this task by means of the study of associations between the profiles of frequencies (Benzecrì, 1973a, 1973b). It is based on the chi-square metric and is used with descriptive aims - that is, with the aim of creating a multidimensional map of the data - rather than confirmatory ones. MCA disarticulates the overall variance of data matrix (in technical terms: inertia) in factorial dimensions, each representing a specific association among the variables (Venuleo, Mossi, \& Salvatore, 2014). In our case, MCA allowed to depict how defense mechanisms associate with each other within the various sessions. In so doing, the MCA provided a map of the evolution of the patterns of defense mechanisms throughout the course of psychotherapy. In order to apply MCA to our case, we differentiated among low and high use of each DMRS defensive mechanisms for each session. To this end, we computed the mean of each defense mechanism throughout the whole therapy; then for each session each defense level was categorized as low if its level in the session was lower than the overall mean, or high if it was higher than the overall mean. Then, a Xi,j matrix was obtained with $i$ indicating the sessions and $j$ the defense mechanisms. Each cell of the matrix reports the level of the $j$-th defense mechanism (high, $\mathrm{H}$ or low, $\mathrm{L}$ ) in the $i$-th session. The period of therapy - banded in three segments ( $\mathrm{T} 1, \mathrm{~T} 2$ and $\mathrm{T} 3$ according to the procedure) - was used as illustrative variable. In so doing, we were able to define if the identified defense mechanism patterns were characteristic of specific periods of therapy. This allowed us to map the evolution of defense mechanism patterns throughout the course of psychotherapy (for a similar use of MCA see Gennaro, Goncalves, Mendes, Ribeiro, \& Salvatore, 2011; Salvatore, Gelo, Gennaro, Manzo, \& AlRadaideh, 2010; Venuleo, Salvatore, \& Mossi, 2014).

\section{Results}

\section{Assessment: Case formulation}

According to SWAP-200-A PD scores, Gabriele shows an Obsessive personality disorder feature ( $\mathrm{PD}=$ 55.04). Moreover, the $Q$ factor scores indicate a narcissistic personality feature $(\mathrm{Q}=58.09)$ and the only score representative of Gabriele's personality is the inhibited self-critical image $(Q=68.65)$. The SWAP200-A items scored 6 and $7^{3}$, indicate that Gabriele tends to be anxious, withholding and very controlling, especially for details; finally he showed a obsessive compulsive / narcissistic profile (see Table 1).

In the first sessions the way Gabriele talked about himself highlighted a very self-critical and blaming attitude:

\footnotetext{
"I am stupid...I know that my anxiety is not necessary but I am not able to manage it...my family is very worried...I am so asshole that I can't recover by myself".
}

\section{Moreover, about homework:}

\footnotetext{
“Today I have to study 52, no...54...no 76 pages...I am not sure, wait...(he brings his school diary from the school bag)...Let me check...68 pages...ok now it is correct, keep going..."
}

\section{Process analysis}

Means and SDs of DMRS were presented in Table 2. A log-linear model was applied to the DMRS levels, with exception for Borderline level that showed very low frequencies along the treatment, which a log-linear model could not interpreted. The general model was significant $\left(\chi_{\mathrm{rc}(10)}^{2}=62.839 p<.001\right)$. Row (Periods: $Y_{\mathrm{r}(2)}^{2}=6.08 \mathrm{p}<.05$ ), Column (DMRS levels: $\left.Y^{2}{ }_{c(5)}=12.00 p<.05\right)$, and Interaction $\left(Y^{2}{ }_{\mathrm{rc}(12)}=\right.$ $60.21 p<.001$ ) had significant effects (Table 3 ). 
Table 1. Descriptive items of SWAP-200-A at assessment phase and at the end of therapy

\begin{tabular}{|c|c|}
\hline Assessment Profile & End of therapy Profile \\
\hline $\begin{array}{l}\text { He is troubled by recurrent obsessive thoughts } \\
\text { that he experiences as senseless and intrusive. } \\
\text { He tends to be preoccupied with concerns about } \\
\text { dirt, cleanliness and contamination. } \\
\text { He has difficulty discarding things even when } \\
\text { worn-out or worthless, and tends to hoard, collect, } \\
\text { or hold onto things. } \\
\text { He tends to be stingy and withholding (whether } \\
\text { of money, ideas, emotions, etc.). } \\
\text { He is overly concerned with rules, procedures, or- } \\
\text { der, organization, and schedules, and adheres rigidly } \\
\text { to daily routines and becomes anxious or uncom- } \\
\text { fortable when they are altered. } \\
\text { He tends to be superstitious or believes in magical } \\
\text { or supernatural phenomena (e.g., astrology, tarot, } \\
\text { crystals, ESP, "auras," etc.). } \\
\text { He tends to be controlling and to become ab- } \\
\text { sorbed in details, often to the point that he misses } \\
\text { what is significant in the situation. } \\
\text { He expects himself to be "perfect" (e.g., in } \\
\text { achievements, performance). } \\
\text { He tends to think in abstract and intellectualized } \\
\text { terms, even in matters of personal import. } \\
\text { Gabriele showed moral and ethical standards and } \\
\text { strives to live up to them. } \\
\text { He is self-critical, usually setting unrealistically } \\
\text { high standards for himself and is intolerant of his } \\
\text { own human defects. } \\
\text { Sometimes his beliefs and expectations seem cli- } \\
\text { chéd or stereotypical, as if taken from story-books or } \\
\text { movies. } \\
\text { He tends to "catastrophize"; is prone to seeing } \\
\text { problems as disastrous, unsolvable, etc. } \\
\text { He tends to be angry or hostile (whether con- } \\
\text { sciously or unconsciously) and usually has difficulty } \\
\text { acknowledging or expressing anger. }\end{array}$ & $\begin{array}{l}\text { He enjoys challenges and takes pleasure in ac- } \\
\text { complishing things. } \\
\text { He is capable of listening to information that is } \\
\text { emotionally threatening and can use and benefit } \\
\text { from it, is articulate, and is now able to express him- } \\
\text { self well in words. } \\
\text { Gabriele tends to express affect in terms which } \\
\text { are appropriate to the quality and intensity of the } \\
\text { situation at hand. } \\
\text { He generally finds contentment and happiness in } \\
\text { life's activities, although sometimes he still tends to } \\
\text { think in abstract and intellectualized terms, even in } \\
\text { matters of personal importance. } \\
\text { He still tends to be conscientious and responsible } \\
\text { and is sometimes anxious. } \\
\text { He tends to feel unhappy, depressed, or despond- } \\
\text { ent and is sometimes still troubled by past recurrent } \\
\text { obsessional thoughts. } \\
\text { He tends to be overly concerned with rules and } \\
\text { school schedules and still showed a tendency to be } \\
\text { controlling. } \\
\text { He always expects himself to be "perfect", espe- } \\
\text { cially in achievements. } \\
\text { Sometimes he still experiences difficulty in dis- } \\
\text { carding things even when they are worthless, and } \\
\text { still tends to hoard and collect. } \\
\text { If faced with criticism, he may react with feelings } \\
\text { of rage or humiliation. } \\
\text { He tends to be angry or hostile (whether con- } \\
\text { sciously or unconsciously), and adheres rigidly to } \\
\text { daily routines and becomes anxious or uncomforta- } \\
\text { ble when they are altered. }\end{array}$ \\
\hline
\end{tabular}

In terms of the whole treatment period, Gabriele showed a significantly higher presence of Disavowal defenses and significantly lower frequencies of Mature defenses. With Disavowal mechanisms, Gabriele tended to resolve emotional conflict by avoiding perceiving or consciously acknowledging the more unpleasant aspects of external reality. He was more prone to use Rationalization in order to deal with the situations that stressed him using to elaborate, reassuring but incorrect and incomplete, explanations. Gabriele scarcely used Mature defense that implies good adjustment skills and high adaptive levels in dealing with stressful reality.

From the first month of therapy, the therapist asked about friends:

"Mmh... I have no friends, just schoolmates... Friends are so time-consuming, you have to call them, spend some time with...It is fine with me not having friends, I do not need other people around me..I have many siblings".
About family, when therapist asked him if it could be difficult to share this bedroom with his littlest brother:

"Difficult? Not at all. My mother is very tired, so sometime I woke up in the night to soothe him...it is easy and it is my duty of older brother...".

Regarding the overall defensive mechanisms along the treatment (Periods), Gabriele showed significantly lower frequencies of defense mechanisms in T2, which considered the central part of the treatment, and Gabriele appeared psychologically more open to his painful experiences.

Regarding the trends of specific levels during the treatment (Interaction Period X DMRS levels), Obsessional and Narcissistic levels decreased significantly from $\mathrm{T} 1$ to $\mathrm{T} 3$. According to the Obsessional Level, Gabriele became more open to the affective meaning of his experiences. In particular, Undoing (or Retroactive Annulment) decreased. At the beginning of the treatment the patient tried to 'undo' an $u$ 
Table 2. Means and Standard Deviations of DMRS Defense Levels on T1, T2 and T3

\begin{tabular}{|c|c|c|c|c|c|c|}
\hline & \multicolumn{2}{|c|}{$\begin{array}{c}\mathrm{T} 1 \\
\text { Assessment Phase }\end{array}$} & \multicolumn{2}{|c|}{$\mathrm{T} 2$} & \multicolumn{2}{|c|}{$\begin{array}{c}\text { T3 } \\
\text { Outcome }\end{array}$} \\
\hline & $M$ & $S D$ & $M$ & $S D$ & $M$ & $S D$ \\
\hline 1. Acting & 6.50 & 3.79 & 5.75 & 2.87 & 5.00 & 3.16 \\
\hline 2. Borderline & .50 & .58 & 1.50 & .58 & .50 & 1.00 \\
\hline 3. Disavowal & 10.25 & 2.63 & 8.00 & 1.82 & 6.50 & 1.29 \\
\hline 4. Narcissistic & 9.50 & 5.00 & 4.00 & 3.16 & 4.50 & 1.20 \\
\hline 5. Neurotic & 5.25 & 2.36 & 6.50 & 1.00 & 5.75 & .96 \\
\hline 6. Obsessive & 9.75 & 4.11 & 7.00 & 7.44 & 5.00 & 1.63 \\
\hline 7. Mature & 1.50 & 1.29 & 2.00 & 2.16 & 3.25 & 2.63 \\
\hline ODF & 3.94 & .34 & 3.93 & .18 & 4.12 & .70 \\
\hline
\end{tabular}

Note. ODF $=$ Overall Defensive Functioning

Table 3. Parameter estimates for period and DMRS defnsive mechanisms and their interactions, and the probability of the standardized parameters

\begin{tabular}{lccccccc}
\hline Period & Mature & Obsessive & Neurotic & Narcissistic & Disavowal & Action & Overall \\
\hline T1 & $-3.211^{* *}$ & $2.022^{* * *}$ & -1.272 & $3.314^{* * * *}$ & $1.636^{*}$ & 0.333 & 0.986 \\
T2 & -1.405 & 0.246 & $1.650^{*}$ & -1.211 & 0.761 & 0.853 & $-1.686^{*}$ \\
T3 & $6.272^{* * * *}$ & $-2.067^{* * *}$ & -0.3150 & $-1.674^{*}$ & $-1.986^{* * *}$ & -1.161 & 0.759 \\
All treatment & $-3.433^{* * * *}$ & 1.470 & 0.164 & 0.065 & $3.441^{* * * *}$ & 0.164 & \\
\hline
\end{tabular}

Note. T1 = Time $1-$ Assessment. T2= Time 2. T3= Time 3 - Outcome

${ }^{* * * *} \mathrm{p}<.005,{ }^{* * *} p<.01,{ }^{* *} p<.025,{ }^{*} p<.05$ one-tailed

nhealthy, destructive or otherwise threatening thought by engaging in contrary behaviors. This mechanism is related to a sense of control that he tried to exert on his impulses; for example anger that he was not able to express freely in the first part of the treatment. Regarding the Narcissistic Level, the clear decrease in these strategies highlights that in the last part of the treatment Gabriele was able to regulate his self-value without distorting the image of the self that he had employed to regulate self-esteem in T1. Devaluation of Self and Other decreased. Gabriele became more prone to considering himself and others as suitable, lovable and nice. Thus his rigid pattern of self and other deprecation become less pervasive in his psychological functioning. This allowed Gabriele to be more open and trusting with himself and others. Moreover, Disavowal defenses were significantly less frequent in T3, meaning that Gabriele's pattern of Rationalization was no longer part of the most representative defense in the last part of the treatment. Neurotic Level was significantly more frequent in T2, and Repression and Displacement seemed to characterize this pattern. In the central phase, due to the elaboration of core conflictual themes, Gabriele was closer to his affective world. Neurotic Level was often activated when feelings and emotions were finally aroused but he still had difficul- ty dealing with them openly, and so conscious perceptions of instincts and feelings were still partially blocked. Finally, Mature defense increased significantly from T1 to T3, and Self-observation and Selfassertion seemed to characterize this pattern. Gabriele became more able to think about what was happening to him, to his feelings, and to organize specific and concrete actions to deal with stressors. This process maximizes gratification and allows the conscious awareness of feelings, ideas, and their consequences.

At the end of the therapy, talking about himself and his siblings:

"I discovered to be good in keeping secrets and give good advices: my sister A. looks for me when he has some problems. It is very nice to talk with her. She is sweet, sometime she would like to give me a kiss, but I still a little shy for this...(laugh)"

The MCA described two main factors able to explain the $74,5 \%$ of the total inertia (see Table 4) and describing the use of defense mechanisms during treatment. The first factor is characterized by denial, narcissistic and other neurotic defense mechanisms (as defined by Perry, 1990). The joint use of these mechanisms highlights a basic narcissistic condition able to maintain the integration of self through 
Table 4. Description of factors as highlighted by the MCA

\begin{tabular}{|c|c|c|c|c|c|}
\hline Factor & $\begin{array}{c}\text { Factor } \\
\text { interpretation }\end{array}$ & Variable & Modalities & Test-Value & Weight \\
\hline \multirow{7}{*}{1} & \multirow{7}{*}{$\begin{array}{c}\text { Narcissistic } \\
\text { defensive } \\
\text { pattern }\end{array}$} & Denial mechanisms & 3_H & -3.01 & 5 \\
\hline & & Narcissistic defenses & 4_H & -2.99 & 4 \\
\hline & & Other neurotic defenses & 5_L & -2.40 & 5 \\
\hline & & Mid Zone & & & \\
\hline & & Other neurotic defenses & 5_H & 2.40 & 7 \\
\hline & & Narcissistic defenses & 4_L & 2.99 & 8 \\
\hline & & Denial mechanisms & 3_L & 3.01 & 7 \\
\hline \multirow{5}{*}{2} & \multirow{5}{*}{$\begin{array}{c}\text { Maturity in } \\
\text { defensive } \\
\text { strategies }\end{array}$} & Mature defenses & 7_L & -2.07 & 8 \\
\hline & & Border defenses & 2_H & -2.01 & 7 \\
\hline & & Mid Zone & & & \\
\hline & & Border defenses & 2_L & 2.01 & 5 \\
\hline & & Mature defenses & 7_H & 2.07 & 4 \\
\hline
\end{tabular}

the joint use of mechanisms implying a partial distortion of reality (Bond, 1986; Kernberg, 1994). In particular, the positive semi-axis identifies a low use of this narcissistic defensive pattern while the negative semi-axis represents a high incidence of it. The second factor (see Table 4) is characterized by the use of mature or border defense mechanisms - when the former is present the latter are not, and vice versa. According to Kernberg (1994,) and Bond (1986), this dimension could be interpreted as an opposition between the uses of mature versus non-mature defensive strategies. In particular, the negative semi-axis represents high border, non-mature mechanisms, and the positive semi-axis mature mechanisms.

The two factors have been used as geometrical dimensions of a Cartesian space (see Figure 1). The three segments of time have been plotted in Cartesian space to track the evolution of the defense mechanism patterns through time. The closer a segment of time is to the polarity of a factor, the greater its association with the pattern of defense mechanism depicted by the polarity.

A visual inspection of the Cartesian space highlights a clear temporal trend associated with the patterns of defense mechanisms. The first period of treatment (T1) is associated to a pattern of narcissistic and non-mature defensive strategies; T2 is characterized by the decreasing in the narcissistic pattern, yet it is associated with an increasing in non-mature defenses. In the final part of the treatment (T3), the low level of narcissistic defensive pattern is maintained, yet this time in association with a high level of use of mature defense mechanisms. In sum, throughout the treatment, it is possible to identify a trajectory indicating an initial strong use of a narcissistic pattern, which is then reduced in T2. This reduction in the narcissistic pat- tern seems to have an effect of de-structuring Gabriele's basic equilibrium, feeding a regression toward the use of less mature defenses. At end of the clinical process (T3) this regression is overcome, and leaves room for the use of mature defensive strategies able to sustain the weakened narcissistic pattern.

\section{Outcome: case formulation}

According to SWAP-200-A, at the end of the treatment Gabriele showed a significant positive high level of functioning on PD scores $(P D=67.44)$. The $Q$ factor indicates that he maintained an inhibited self-critical image on a clinical range. However, this self-image, linked to the increased high level of functioning, represented a nuance of personality rather than a psychopathological aspect per se. SWAP-200-A during the assessment phase and at the end of the treatment was also compared on a statistical level using the Wilcoxon rank-sum test. PD SWAP-200-A scores for the initial assessment phase and the conclusion phase showed a significantly different rank distribution $(z=-1.60, \mathrm{p}<.05)$ confirming a higher level of functioning than personality impairments at the end of the treatment. According to $\mathrm{Q}$ factors, rank distribution did not show statistical change $(z=-68, p=.50)$.

At the end of the therapy:

"I looked at the calendar...the therapy is over in few session...mhmm...I remember that I considered my-self an asshole, now I do not think so anymore...Sometimes I still think to be stupid, but anyway... I'm funny...I makes my sister laugh ..."

Gabriele's Narrative profile at the end of the treatment showed that he is able to use his talents, 


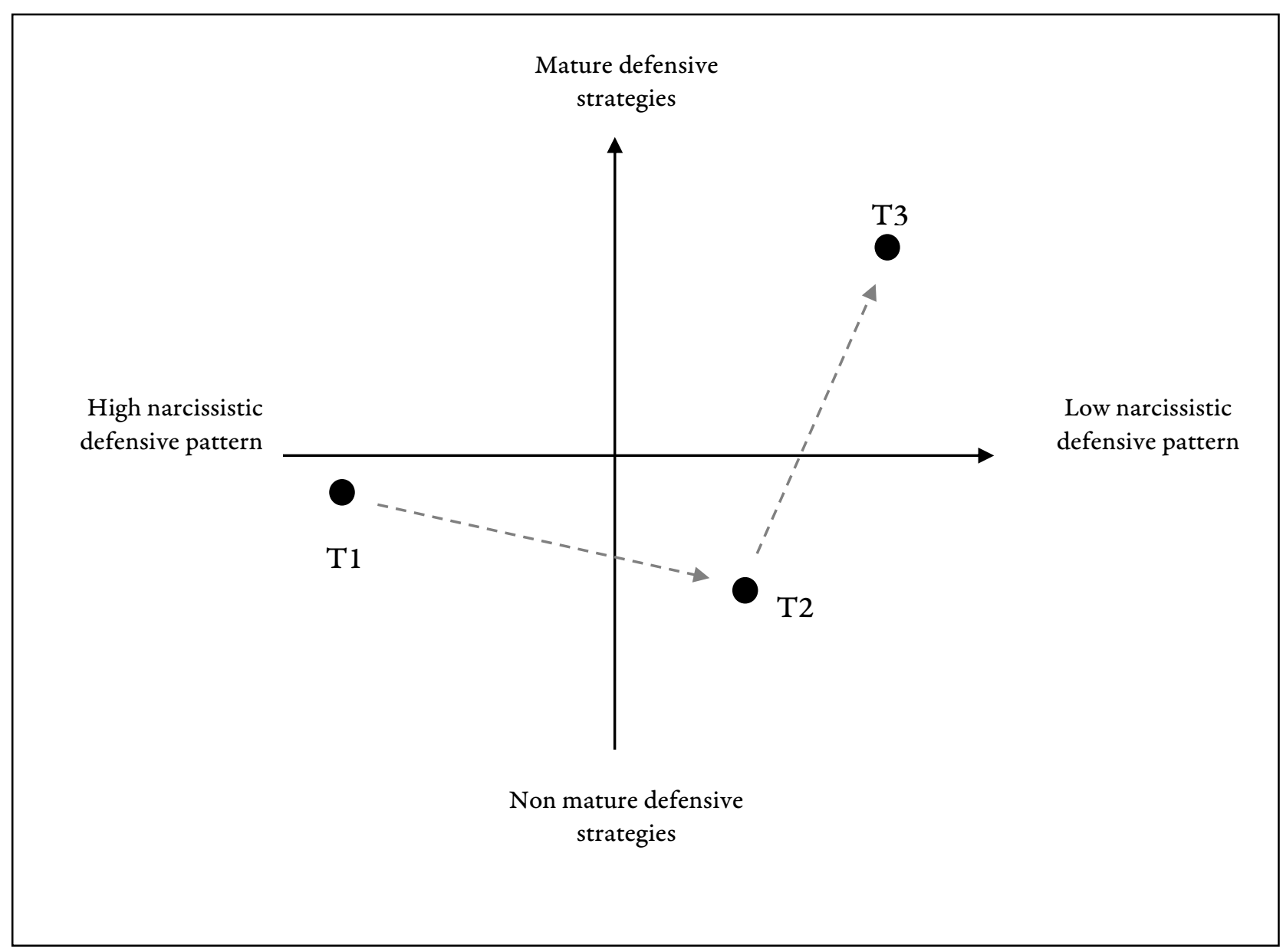

Figure 1. Factorial space obtained by the MCA, describing 3 treatment periods

abilities, and energy effectively and productively (see Table 1).

\section{Discussion}

This paper examines changes in personality structure measured by SWAP-200-A and defensive functioning using DMRS over the course of a 2-year non-i ntensive psychoanalytically oriented psychot herapy with an early adolescent boy. Gabriele's case formulation at the beginning of the treatment was conducted by combining the DSM-IV diagnosis and the SWAP-200-A. Case formulation during the assessment phase described Gabriele's complex picture. DSM-IV Axis I revealed a diagnosis of GAD. Literature with adolescent outpatients has highlighted that obsessional mechanisms correlate with diagnostic anxiety features (Offer, Lavie, Gothelf, $\&$ Apter, 2000). This pattern was confirmed by the high prevalence of Obsessional Level mechanisms in T1. SWAP-200-A PD scores did not show a strict personality disorder but highlighted obsessive personality features, in line with DMRS scores at T1. At the beginning, Gabriele presented great use of Disavowal defenses, through which he tended to handle emotional conflict by avoiding processing unpleasant aspects of external and internal reality.
However, this could not be considered clinical, but typical of his developmental stage (Cramer, 2001). In the same way, the low presence of Mature defenses could be explained by the fact that the normal psychological development of early adolescents does not allow for the elaboration of such complex strategies (Cramer, 2001). Further, the $Q$ factor outlined a boy with narcissistic difficulties. As Westen and Shedler (2000) pointed out, narcissistic aspects detected by SWAP-200-A are characterized by mixed symptoms nearby also with obsessive personality, confirming Gabriele's dysfunctional behaviors in being excessively tidy, perfect and tormented by pervasive and unrealistic thoughts about his parents' health. According to Westen (1990), a narcissistic Q factor in SWAP-200-A should be considered not only as a category or personality disorder, but also as a descriptor of developmental motions and personality development including identity definition, self-esteem, and the ability to invest in relationships (Williams et al., 2009). This was also confirmed by the massive use of Narcissistic defenses in T1, which, as Anna Freud (1936) pointed out, are mechanisms very typical of early adolescence and adolescence. In fact, in this phase adolescents show a strong involvement in themselves and a clear need to manage their self-esteem by dis- 
torting the image of the self and the others. Gabriele was very severe with himself, considering himself weak and inadequate regarding, for example, school achievement, and set himself unrealistic goals. He also undervalued important relationships, such as his younger siblings and his schoolmates, in order to nurture his personal values which were already strongly compromised. The $\mathrm{Q}$ factor also highlighted an inhibited self-critical image. This style is linked to early-adolescents and adolescent functioning showing a high control of emotions and impulsive behaviors (Westen et al., 2006). This feature fits with Gabriele's functioning by describing a tendency to be perfectionist, and to be in charge of family activities. In fact, on intake, the young patient presented a rigid moralistic attitude towards being responsible for his siblings' education, homework and shared family tasks. A reduction in symptoms at the outcome assessment was confirmed statistically by the SWAP-200-A. At the assessmentbeginning phase and conclusion phase, the SWAP200-A reported a significantly different rank distribution showing lower levels of personality impairment at the end of the treatment. A lower level of narcissistic and obsessive attitudes and a higher score for high level functioning were present. The psychotherapy process helped him use his talents and although at the outcome assessment the inhibited self-critical image was positive, combined with the gained high level functioning could be considered as a developmental attitude (Westen et al., 2003). This improvement in personality could be interpreted as a chance for Gabriele to use his defensive pattern in a more adaptive way. The supportive psychoanalytically oriented psychotherapy helped him face the structural troubles by offering new resources to handle them (Hoffman, 2002). At the end of therapy, maladaptive personality features had improved presenting a modified portrait of Gabriele as less severe. Therapeutic intervention tailored a 'good enough' ground to begin to accomplish his developmental tasks. He became less devoted to managing the weekly schedule for the entire family and focused more on his new friends and social activities.

From a clinical perspective, T2 was considered the core part of the treatment and Gabriele seemed to be more engaged in the therapeutic relationship and psychologically more able to elaborating his painful experiences rather than defending them. A significant lower frequency of defensive mechanisms was associated to an improvement in quality of defensive functioning: Mature defenses increased, and Disavowal, Obsessional and Narcissistic (Immature defenses) decreased. From a clinical perspective, the decrease in Obsessional defenses is very meaningful since Gabriele's initial dysfunctional diagnosis was strictly related to those mechanisms. The literature shows that recovery from psy- chological disease is associated with a decreased use of immature defenses and an increased use of mature defense (Ackerman, Lewin, \& Carr, 1999; Albucher, Abelson, \& Nesse, 1998; Porcerelli et al., 2007; Porcerelli, Cogan, Kamoo, \& Miller, 2010). This also seems to be true with developmental age patients, although they typically show a generally more immature pattern of defenses in respect to adults, due to their developmental stage (Freud, 1936; Cramer, 2001). In fact, at the end of treatment, Gabriele's ODF remained on the $4^{\text {th }}$ level (Narcissistic defenses) but this was in line with the adolescent period (Freud, 1936; Cramer, 2001). Gabriele dealt with his anxiety about the sense of self, reality, relationship and wishes with defenses (Lingiardi \& Madeddu, 2002; Vaillant, 1992). In fact, although Mature defenses are not characteristic of early adolescence and adolescence, the therapeutic relationship allowed Gabriele to use high functioning defensive mechanisms which meant that he could handle stressors in a more integrated way (Cramer, 2001; Fonagy, 2005; Gabbard \& Twemlow, 1994; Hoffman, 2002; Porcerelli et al., 2010). At the same time, the treatment helped reduce Obessional defenses. This is extremely relevant since the Obsessional mechanisms were characteristic of Gabriele's intake diagnosis and symptomatic behaviors, representing his specific dysfunctional pattern. During the psychotherapy process, Gabriele's skills improved starting from his attitude toward himself and the external world. He became more able to use his resources and he finally started to integrate his cognitive and affective aspects. The changes in Gabriele's capacity to connect with his feelings, suggested by the decrease in obsessional defenses and increase in high functioning levels of the SWAP-200-A, which also evaluated the patient's capacity to bear potentially threatening emotions, seemed to highlight the psychoanalytically-oriented therapeutic work which encourages exploration of patient emotions during different phases (Shelder, 2010).

These results agreed with Gabbard's (2009) considerations that in non-intensive therapies, maladaptive mechanisms need to be treated and interpreted, in order to be reduced. Indeed, the literature reports the possibility of supportive intervention to achieve structural changes, also in terms of defensive mechanism patterns (Di Riso et al., 2011; Hoffman, 2002; Wallerstein, 1989).

Gabriele's use of defense mechanisms was analyzed among the treatment processes throughout the MCA. Results highlighted a change, showing a developmental trajectory concerning the use of defense mechanisms, as hypothesized. A quantitative decrease in the use of defense mechanisms previously highlighted reflected an improvement in developmental dimensions over time of the defense mechanism patterns characterizing the patient sessions. On 
the whole, this perspective seems to be in line with the literature sustaining that one of the aims of therapeutic treatment is to promote a reduced use of maladaptive defensive mechanisms in order to promote the use of more mature and more adaptive strategies (Ackerman et al., 1999; Albucher et al., 1998; Porcerelli et al., 2007; Porcerelli et al., 2010).

Analyzing data from MCA, at the beginning of the treatment process, Gabriele's usual way of using defense mechanisms in the interface between himself and world experience were described: $\mathrm{T} 1$ shows Gabriele's strong narcissistic defensive pattern as used jointly with low mature defense mechanisms. This condition is also confirmed by the initial personality assessment using SWAP-200-A, where the $Q$ factor highlighted narcissistic difficulties closely linked to a great and high-cost use of disavowal defenses. Accordingly, T1 represents Gabriele, within the clinical setting, as displaying maladaptive means of confronting internal and external realities, characterized by a high narcissistic functioning and low maturity in how he copes with external reality, which sustained the need for asking psychological treatment. The second period of the treatment highlighted a change in Gabriele's defensive pattern characterized by a weakening of the narcissistic pattern associated with maintaining, and somehow strengthening, his non-mature defensive mechanisms.

It should be noted that this part of the clinical process may be seen as a transition phase in which the patient can experience the possibility of using a new way to represent himself and to face internal and external needs. On the other hand, maintaining non-mature defense mechanisms underlines the need to make use of cost-adaptive but well-known defensive modalities once the narcissistic pattern has been destabilized. This condition leads, in a non-gradual and non-linear way (Salvatore, LauroGrotto, Gennaro, \& Gelo, 2009) to a change in the final part of the therapeutic intervention, where Gabriele's use of defense mechanisms could be described as maintaining a weakened narcissistic pattern associated with the use of mature defense mechanisms.

Following two brief excerpts from the treatment that illustrate from a clinical point of view the change according to Gabriele functioning. Both of them focused on his symptoms.

The following is from $\mathrm{T}^{2}$ :

Gabriele: "I collected dvd movies. They are in a shelf in my bedroom. They...are in order. It is normal for me, I do not like chaos...I think that it is not polite to have dvd movies in disorder. Sometimes my dad come to get one of those...He knows he had to sign on a piece of paper which dvd he gets...I need to know where is my dvd, and how long it misses from the shelf"

Therapist: "Oh...It must be very complicated for you..:

G: "No, no...it is not complicated for me...It is polite for someone who borrows your stuff to tell you where are your stuff and how much time he needs it..."

$\mathrm{T}$ : "What could happen if your dad forgets to write down this information?"

G: "I do not know. It never happens"

$\mathrm{T}$ : "I see...please try to image a situation like this"

G: "It is impossible to me..."

$\mathrm{T}$ : "It seems to me that it is impossible to think about a your possible reaction...

G: "Yes...cause it is impossible that my dad could forget this"

T: "Why?"

$\mathrm{G}$ : "He is very precise, he does not like disorder"

The following is from T3:

Therapist: "What about your dvd shelf?"

Gabriele: "Oh I still have it.. (laughing). It was so useful for me in the past years... I kept to clean and tidy it up...oh gosh (laughing).

$\mathrm{T}$ : "Have you ever thought about what did you try to tidy up, tiding up it?"

G: "Oh...it was so disturbing for me to see a chaotic shelf"

T: "How do you mean for disturbing?"

G: "It make me angry...the chaos makes me angry...and I thought it was not polite..."

$\mathrm{T}$ : "It is very interesting what are you saying. So maybe for you it was not polite to be angry"

G: "Yeah...In this last year I discussed with my parents...it was not easy for me...I kept thinking about it for days and days. I was scared they could become sad for this...I also fought with my school mates...it was very nice noticing that the next day they forgot our discussion, and they were again nice with me...They starts liking me...they love to hear me playing my guitar...

$\mathrm{T}$ : "It seems that even you became angry, you did not destroy your relationships"

G: "Yes, chaos is not so dangerous...not yet funny...but not so dangerous.

$T$ : What do you usually play?

G: "One of my school mate suggests me to play American country music...so nice...I do not dance, of course (laughing)..but they do...and we have fun..."

This two excerpts highlight from a clinical point of view the different level of functioning and awareness about his symptoms. In T1, Gabriele was very rigid in thinking about his distress. Although he recognized to be excessively tidy, his mind was not yet able to process the affective burden of this condition but he considered it as natural features of polite individuals (himself and his father). Clinician interventions in that direction were by-passed. In 
this first part of the treatment, he focused just on symptoms, and what happened in their house. In T3, Gabriele changed the way to think about his symptoms: his mind is more flexible and he is able to integrate the affective domain in a previous sterile context. He was able to slightly laugh about his shelf (his symptoms) and to think about the meaning of that, building a bridge between the need to keep in order something external and something internal. He also integrated the sessions with references to his relationships with classmates, in which he could experience the good meaning of "chaos".

\section{Conclusions}

The present paper has examined changes in personality structure and defense use over the course of a 2year non-intensive psychoanalytically oriented treatment with an early adolescent boy referred for severe anxiety. This study has tried to highlight how a psychodynamic non-intensive treatment might by effective with a young patient referred for anxiety. This aspect is in line with Muratori, Picchi, Bruni, Patarnello and Romagnoli (2003) who demonstrated that psychodynamic intervention is effective in treating internalizing disorders in outpatients. It may be difficult, therefore, to understand how much psychological functioning was a result of the therapeutic action, and not just due to early adolescent psychological growth. In the assessment phase, Gabriele's personality structure was primitive and his defenses mechanisms use was massive and their quality were not adaptive. From a clinical perspective, the patient presented a severe level of functioning also according to his age. For these reason we hypothesized that Gabriele's improvement was mostly a result of psychotherapy, even psychological changes in developmental age might have been influenced by any number of other physical, psychological and contextual processes that were not assessed.

The present paper specifically discussed outcome and process issues in terms of personality structural changes assessed by SWAP-200-A and defense mechanisms as measured by DMRS, respectively. According to the data, the clinical intervention could be considered in terms of a general functioning model (Gennaro, 2011; Salvatore et al., 2010). On the whole, the treatment process seemed to work over two different phases: a deconstructive stage characterizing $\mathrm{T} 1$ and $\mathrm{T} 2$, in which the clinical process is directed toward weakening the presented narcissistic defensive pattern, and a constructive stage (T2 and T3) devoted to promoting the use of mature defensive schemes in association with maintaining a weakened narcissistic pattern.

To the best of the authors knowledge, this is a first paper that has systematically highlighted that defensive mechanisms using DMRS and personality structure change over long term treatment can also be identified in a young patient. Moreover, in the literature, papers using SWAP-200-A and DMRS together in developmental age are not available. Several studies have implied the assessment of audio-recorded and fully transcribed sessions in the treatment of children and adolescents, but they did not include defense evaluation (Chazan \& Wolf, 2002; Duncan, 2006; Harrison, 2003). Some authors analyzed defense mechanisms in clinical adolescents only by means of self-report measures (Offer et al., 2000). However the integration of SWAP200-A with defenses mechanisms scored in the transcripts could help clinicians to conceptualize changes during the intervention, and detect complex dynamics of the therapist-patient process that could identify both improvement and regression of the patient's personality through psychotherapy (Porcerelli et al., 2011). In a wider perspective, the present work underlines some methodological issues in psychotherapy research, the need to analyze processes of change in the light of general models by means of an analysis of the trajectories of change, and how such an approach could be helpful in explaining clinically the differences highlighted in the treatment. One of the clinical repercussions of this kind of study is to give merit also to nonintensive psychoanalytically oriented psychotherapy in adolescence. In the very present, it is harder and harder to engage parents in supporting intensive treatment for their children. This study suggested that also not intensive treatments could have good outcomes in the internalizing domain and they could be assessed using standardized tools

However, the present study has some limitations. First, this paper focuses on a single case study; therefore the conclusions might not be generalized to other patients with the same diagnosis. Second, the sessions analyzed for the process dimension were only $25 \%$ of Gabriele's whole treatment. Third, the choice to divide the process into three periods was related to the natural divisions, which occurred during the psychotherapy (i.e. holidays). This method did not take into account specific patient "life events" which could have affected the course of the therapy. Psychotherapy process were assessed only from the patient's perspective, not including dimensions related to the therapist (e.g. therapeutic intervention) or to the therapeutic couple (e.g. working alliance). It may be difficult, therefore, to interpret defense mechanism variations as a result of the therapeutic action, and not just due to early adolescent psychological growth. Finally, personality structure and defense mechanisms might have been influenced by any number of other psychological and contextual processes that were not assessed.

Although the results regard only a single case, they highlight the importance of assessing defenses and personality in treatment research and provide 
empirical support for some aspects of process and outcome with young patients.

\section{Note}

1. Researchers have obtained written informed consent with confidentiality formula, both for audiorecording and for the publication of the research, by parents and patient; although, names and personal information were substantially changed.

2. Six DMRS levels were involved in the log-linear procedure, and 3 were the periods of the treatment.

3. SWAP-200-A narrative profile included items scored 5, 6, and 7; we decided to show in Table 1 just item scored 6 and 7, to highlight macrochanges in the patient functioning and to avoid a very long and detailed description.

\section{References}

Ackerman, K., Lewin, T., \& Carr, V. (1999). Long-term changes in defense style among patients recovering from major depression. Journal of Nervous and Mental Disease, 187(2), 80-87. doi: 10.1097/00005053-199902000-00003

Albucher, R. C., Abelson, J. L., \& Nesse, R. M. (1998). Defense mechanism changes in successfully treated patients with obsessive-compulsive disorder. American Journal of Psychiatry, 155(4), 558-9. doi: 10.1176/ajp.155.4.558

American Psychiatric Association (Eds.). (1980). Diagnostic and Statistical Manual of Mental Disorders, Third Edition. Washington, DC.

American Psychiatric Association (Eds.). (1994). Diagnostic and Statistical Manual of Mental Disorders, Fourth Edition. Washington, DC.

American Psychiatric Association (Eds.). (2000). Diagnostic and statistical manual of Mental Disorders, Fourth Edition, Text Revision (DSM-IV-TR). Washington, DC.

Benzecri, J. P. (Ed.). (1973a). L'Analyse des données. Tome I: La taxonomies. Data analysis. Volume I: The taxonomy. Paris: Dunod.

Benzecri, J. P. (Ed.). (1973b). L'Analyse des données. Tome II: Correspondances. Data analysis. Volume I: The taxonomy. Volume II: Correspondences. Paris: Dunod.

Block, J. (Ed.). (1978). The Q-Sort method in personality assessment and psychiatric research. Palo Alto, CA: Consulting Psychologists Press. See also: http://www.qmethod.org/articles/jack_block.pdf

Bond, M. (1986). Defense style questionnaire. In G. E. Vaillant (Ed.), Empirical studies of Ego Defenses Mechanisms (pp. 146152). Washington DC: American Psychiatric Press.

Chazan, S. E., \& Wolf, J. (2002). Using the Children's Play Therapy Instrument to measure change in psychotherapy: the conflicted player. Journal of Infant, Child \& Adolescent Psychotherapy, 2(3), 73-102. doi: $10.1080 / 15289168.2002 .10486407$

Cramer, P. (Ed.). (1991). The development of defense mechanisms: Theory, research and assessment. New York: Springer-Verlag.

Cramer, P. (2001). Identification and its relation to identity development. Journal of Personality, 69(5), 667-687. doi: 10.1111/1467-6494.695159

Deakin, E. K., \& Nunes, M. L. T. (2009). Effectiveness of child psychoanalytic psychotherapy in a clinical outpatient setting. Journal of Child Psychotherapy, 35(3), 290301. doi: 10.1080/00754170903244621
Di Lallo, J. J., Jones, M., \& Westen, D. (2009). Personality subtypes in disruptive adolescent males. Journal of Nervous and Mental Disease, 197(1), 15-23. doi: $10.1097 / \mathrm{nmd} .0 \mathrm{~b} 013 \mathrm{e} 318192770 \mathrm{c}$

Di Riso, D., Colli, A., Chessa, D., Marogna, C., Condino, V., Lis, A., . . Mannarini, S. (2011). A supportive approach in psychodynamic-oriented psychotherapy. An empirically supported single case study. Research in Psychotherapy, 14(1), 49-89.

Drapeau, M., De Roten, Y., Perry, J. C., \& Despland, J. N. (2003). A study of stability and change in defense mechanisms during a brief psychodynamic investigation. Journal of Nervous and Mental Disease, 191(8), 496-502. doi: 10.1097/01.nmd.0000082210.76762.ec

Duncan, A. (2006). The developmental lines of child psychotherapy process. Unpublished MSc dissertation. Anna Freud Centre / University College: London.

Fonagy, P. (2005). Psychoanalytic Development Theory. In E. S. Person, A. M, Cooper, \& G. O. Gabbard (Eds.), The American Psychiatric Publishing Textbook of Psychoanalysis, (pp. 117-130). New York: American Psychiatric Publishing.

Fonagy, P., Target, M., Cottrell, D., Phillips, J., \& Kurtz, Z. (Eds.). (2005). What works for whom?: a critical review of treatments for children and adolescents. Guilford Press: NY.

Freud, A. (Ed.). (1936). The Ego and Mechanisms of Defense. New York: International. Universities Press, Inc.

Gabbard, G. O. (Eds.). (2009). Textbook of psychotherapeutic treatments. Washington, DC: American Psychiatric Publishing.

Gabbard, G. O., \& Twemlow, S W. (1994). The Role of Mother-Son Incest in The Pathogenesis of Narcissistic Personality Disorder. Journal of the American Psychoanalytic Association, 42(1), 171-189. doi: $10.1177 / 000306519404200109$

Gennaro, A. (2011). The Building of Models as Pathway to Understand the Therapeutic Process. Integrative Psychological and Behavioral Science, 45(3), 355-365. doi: 10.1007/s12124-011-9181-8

Gennaro, A., Goncalves, M., Mendes, I., Ribeiro, A., \& Salvatore, S. (2011). Dynamics of sense-making and development of the narrative in the clinical exchange. Research in Psychotherapy: Psychopathology, Process and Outcome, 14(1), 90-120.

Gerber, A. (2004). Structural and symptomatic change in psychoanalysis and psychodynamic psychotherapy: a quantitative study of process, outcome and attachment. Unpublished PhD thesis, University College London.

Gerber, A. J., Kocsis, J. H., Milrod, B. L., Roose, S. P., Barber, J. P., Thase, M. E., . . . Leon, A. C. (2011). A QualityBased Review of Randomized Controlled Trials of Psychodynamic Psychotherapy. The American Journal of Psychiatry, 168(1), 19-28. doi: 10.1176/appi.ajp.2010.08060843

Gilboa-Schechtman, E., Foa, E. B., Shafran, N., Aderka, I. M., Powers, M. B., Rachamim, L., . . A Apter, A. (2010). Prolonged exposure versus dynamic therapy for adolescent PTSD: a pilot randomized controlled trial. Journal of the American Academy of Child and Adolescent Psychiatry, 49(10), 1034-1042. doi: 10.1016/j.jaac.2010.07.014

Harrison, A. (2003). Change in psychoanalysis: Getting from A to B. Journal of the American Psychoanalytic Association, 51(1), 221-256. doi: 10.1177/00030651030510011201

Hoffman, R. S. (2002). Practical psychotherapy: working with a patient's defenses in supportive psychotherapy. Psychiatric Services, 53(2), 141-142. doi: 10.1176/appi.ps.53.2.141

Karver, M. S., Handelsman, J. B., Fields, S., \& Bickman, L. (2005). A theoretical model of common process factors in youth and family therapy. Mental Health Services Re- 
search, 7(1), 35-52. doi: 10.1007/s1 1020-005-1964-4

Kazdin, A. E. (Ed.). (2000a). Psychotherapy for children and adolescents: directions for research and practice. New York: Oxford University Press.

Kazdin, A. E. (2000b). Understanding change: from description to explanation in child and adolescent psychotherapy research. Journal of School Psychology, 38(4), 337-348.

Kazdin, A. E. (2009). Psychological science's contributions to a sustainable environment: Extending our reach to a grand challenge of society. American Psychologist, 64(5), 339-356. doi: 10.1037/a0015685

Kazdin, A. E., \& Weisz, J. R. (1998). Identifying and developing empirically supported child and adolescent treatments. Journal of Consulting and Clinical Psychology, 66(1), 19-36. doi: 10.1037//0022-006x.66.1.19

Kennedy, E. (Ed.). (2004). Child and Adolescent Psychotherapy: A Systematic Review of Psychoanalytic Approaches. London: North Central London Strategic Health Authority.

Kennedy, E., \& Midgley, N. (Eds.). (2007). Process and Outcome Research in Child, Adolescent and Parent-Infant Psychotherapy: A Thematic Review. London: North Central London Strategic Health Authority.

Kernberg, P. F. (1994). Mechanisms of defense: development and research perspectives. Bulletin of Menninger Clinic, 58(1), 55-87.

Knoke, D., \& Burke, P. J., (Eds.). (1980). Log-linear models: Paper series on Quantitative Applications in the Social Sciences Series No. 07-020. Newbury Park, CA: Sage.

Laor, N., Wolmer, L., \& Cicchetti, D. (2001). The comprehensive assessment of defense style: measuring defense mechanisms in children and adolescents. Journal of Nervous and Mental Disease, 189(6), 360-368.

doi: 10.1097/00005053-200106000-00003

Lingiardi, V., \& Madeddu, F. (Eds.). (2002). I meccanismi di difesa. Teoria, valutazione, clinica. Milano: Raffaello Cortina Editore.

Lingiardi, V., Shedler, J., \& Gazzillo, F. (2006). Assessing personality change in psychotherapy with the SWAP200: a case study. Journal of Personality Assessment, 86(1), 23-32. doi: 10.1207/s15327752jpa8601_04

Llewellyn, S. P., \& Hardy, G. (2001). Process research in the practice of psychological therapy. British Journal of Clinical Psychology, 40(1), 1-21. doi: 10.1348/014466501163436

Lock, J., Le Grange, D., Agras, W. S., Moye, A., Bryson, S. W., \& Jo, B. (2010). Randomized clinical trial comparing family-based treatment with adolescent-focused individual therapy for adolescents with anorexia nervosa. $\mathrm{Ar}$ chives of General Psychiatry, 67(10), 1025-1032. doi: 10.1001/archgenpsychiatry.2010.128

Midgley, N., \& Kennedy, E. (2011). Psychodynamic psychotherapy for children and adolescents: a critical review of the evidence base. Journal of Child Psychotherapy, 37(3), 232-260. doi: 10.1080/0075417x.2011.614738

Muratori, F., Picchi, L., Bruni, G., Patarnello, M., \& Romagnoli, G. (2003). A two-year follow up of psychodynamic psychotherapy for internalizing disorders in children. Journal of the American Academy of Child and Adolescent Psychiatry, 42(3), 331-339.

doi: 10.1097/00004583-200303000-00014

Nakash-Eisikovits, O., Dutra, L., \& Westen, D. (2003). Relationship between attachment patterns and personality pathology in adolescents. Journal of the American Academy of Child and Adolescent Psychiatry, 41(9), $1111-1123$. doi: 10.1097/00004583-200209000-00012

Offer, R., Lavie, R., Gothelf, D., \& Apter, A. (2000). Defense mechanisms, negative emotions and psychopathology in adolescent inpatients. Comprehensive Psychiatry, 41(1), 35-41. doi: 10.1016/s0010-440x(00)90129-9

Perry, J. C. (Eds.). (1990). Defense Mechanism Rating Scales
(DMRS) (fifth edition). Cambridge (MA): Author.

Perry, J. C. (2001). A pilot study of defenses in psychotherapy of personality disorders entering psychotherapy. Journal of Nervous and Mental Disease, 189(10), 651-660. doi: 10.1097/00005053-200110000-00001

Perry, J. C., Høglend, P., Shear, K., Vaillant, G. E., Horowitz, M. J., Kardos, M. E., ... Kagan, D. (1998). Field trial of a diagnostic axis for defense mechanisms for DSM-IV. Journal of Personality Disorders, 12(1), 1-13. doi: 10.1521 /pedi.1998.12.1.56

Porcerelli, J. H., Cogan, R., \& Bambery, M. (2011). The Mental Functioning Axis of the Psychodiagnostic Manual: An adolescent case study. Invited paper, Special Issues: Put the Complex Person Back at the Center-Stage of Personality Assessment. Journal of Personality Assessment, 93(2), 177-184.

doi: 10.1080/00223891.2011.542724

Porcerelli, J. H., Cogan, R., Kamoo, R., \& Miller, K. (2010). Convergent validity of the Defense Mechanisms Manual and the DSM-IV Defensive Functioning Scale. Journal of Personality Assessment, 92(5), 432-438. doi: 10.1080/00223891.2010.497421

Porcerelli, J. H., Dauphin, V. B., Ablon, J. S., Leitman, S., \& Bambery, M. (2007). Psychoanalysis with avoidant personality disorder: A systematic case study. Psychotherapy: Theory, Research, Practice, Training, 44(1), 1-13.

doi: 10.1037/0033-3204.44.1.1

Salvatore, S., Gelo, O., Gennaro, A., Manzo, S., \& AlRadaideh, A. (2010). Looking at psychotherapy as an intersubjective dynamic of sensemaking. A case study with Discourse Flow Analysis. Journal of Constructivist Psychology, 23(3),195-230. doi: 10.1080/10720531003765981

Salvatore, S., Lauro-Grotto, R., Gennaro, A., \& Gelo, O. (2009). Attempts to grasp the dynamicity of intersubjectivity. In J. Valsiner, P. C. M. Molenaar, M. C. D. P. Lyra, \& N. Chaudhary (Eds.). Dynamic process methodology in the social and developmental sciences (pp. 171-190). New York: Springer.

Shedler, J., \& Westen, D. (1998). Refining the measurement of Axis II: A Q-sort procedure for assessing personality pathology. Assessment, 5(4), 333-353. doi: $10.1177 / 107319119800500403$

Shelder, J. (2010). The efficacy of psychodynamic psychotherapy. American Psychologist, 65(2), 98-109. doi: $10.1037 / \mathrm{a} 0018378$

Shirk, S. R., \& Russell, R. L. (Eds.). (1996). Change processes in child psychotherapy: Revitalizing treatment and research. New York: Guilford Press.

Vaillant, G. E. (Ed.). (1992). Ego Mechanisms of Defense: $A$ Guide for Clinicians and Researchers. Washington, DC: American Psychiatric Press.

Venuleo, C., Mossi, P., \& Salvatore, S. (2014). Educational subculture and dropping out in higher education: a longitudinal case study. Studies in Higher Education, 1-22. doi:10.1080/03075079.2014.927847

Venuleo, C., Salvatore, S., \& Mossi, P. (2014). The role of cultural factors in differentiating pathological gamblers. Journal of Gambling Studies. doi: 10.1007/s10899-014-9476-z

Wallerstein, R. (1989). Psychoanalysis and psychotherapy: An historical perspective. International Journal of Psychoanalysis, 70(4), 563-591.

Weisz, J. R., \& Hawley, K. M. (2002). Developmental factors in the treatment of adolescents. Journal of Consulting and Clinical Psychology, 70(1), 21-43. doi: 10.1037/0022006x.70.1.21

Westen, D. (1990). The relations among narcissism, egocentrism, self-concept, and self-esteem: Experimental, clinical, and theoretical considerations. Psychoanalysis and Contemporary Thought, 13, 183-239. 
Westen, D. (1998). Case formulation and personality diagnosis: two processes or one? In J. Barron (Ed.), Making diagnosis meaningful: Enhancing Evaluation and Treatment of Psychological Disorders (pp.111-137). Washington, DC: American Psychological Association.

Westen, D., Dutra, L., \& Shedler, J. (2005). Assessing adolescent personality pathology. British Journal of Psychiatry, 186(3), 227-238. doi: 10.1192/bjp.186.3.227

Westen, D., Gabbard, G., \& Blagov, P. (2006). Back to the future: Personality structure as a context for psychopathology. In R. F. Krueger, \& J. L. Tackett (Eds.), Personality and psychopathology (pp.335-384). New York: Guilford.

Westen, D., \& Muderrisoglu, S. (2006). Clinical assessment of pathological personality traits. The American Journal of Psychiatry, 163 (7), 1285-1287. doi: 10.1176/ajp.2006.163.7.1285

Westen, D., \& Shedler, J. (1999a). Revising and assessing Axis II: I. Developing a clinically and empirically valid assessment method. American Journal of Psychiatry, 156(2), 258-272.

Westen, D., \& Shedler, J. (2000). A prototype matching approach to diagnosing personality disorders toward DSMV. Journal of Personality Disorders, 14(2), 109-126.

doi: 10.1521/pedi.2000.14.2.109
Westen, D., Shedler, J., Durrett, C., Glass, S., \& Martens A. (2003). Personality Diagnoses in Adolescence: DSM-IV Axis II Diagnoses and an Empirically Derived Alternative. American Journal of Psychiatry, 160(5), 952-966. doi: 10.1176/appi.ajp.160.5.952

Westen, D., Shedler, J., \& Lingiardi, V. (Eds.) (2003). La valutazione della personalità con la SWAP-200. Milano: Raffaello Cortina.

Williams, R., Ferrara, M., Aloi, A., \& Gazzillo, F. (2009). La valutazione della patologia della personalità con la SWAP-200-A: Un'applicazione ad un campione clinico di adolescenti italiani. Infanzia e Adolescenza, 8(2), 98-112.

Wirtz, M., \& Caspar, F. (Eds.). (2002). Beurteilerübereinstimmung und Beurteilerreliabilität. Göttingen: Hogrefe.

Zeger, S. L., Irizarry, R. A., \& Peng, R. D. (2006). On time series analysis of public health and biomedical data. $A n$ nual Review of Public Health, 27(1), 57-79. doi: 10.1146/annurev.publhealth.26.021304.144517

Submitted: May 2015

Accepted: September 2015

Published: December 2015 